\title{
Studies of Potential Inversion in an Extended
}

\section{Tetrathiafulvalene}

\author{
Nadine E. Gruhn, Norma A. Macías-Ruvalcaba and Dennis \\ H. Evans* \\ Department of Chemistry, University of Arizona, Tucson, AZ 85721, \\ U.S.A.
}

\section{Supporting Information}

\section{Contents}

Figure S1. PES spectrum of 2

Figures S2-S7. Comparison of simulations with experimental voltammograms for 0.77 $\mathrm{mM} 2$ in $0.10 \mathrm{M} \mathrm{Bu}_{4} \mathrm{NPF}_{6} / \mathrm{DMF}$ at $25^{\circ} \mathrm{C}$. Concerted: simulations based on Reactions 1 and 2 which consider structural change and electron transfer to be concerted. Simulation parameters in Table 1. Two-step: simulations based on the mechanism in Scheme 1 in which structural change can precede or follow electron transfer. Simulation parameters in Table 2. 


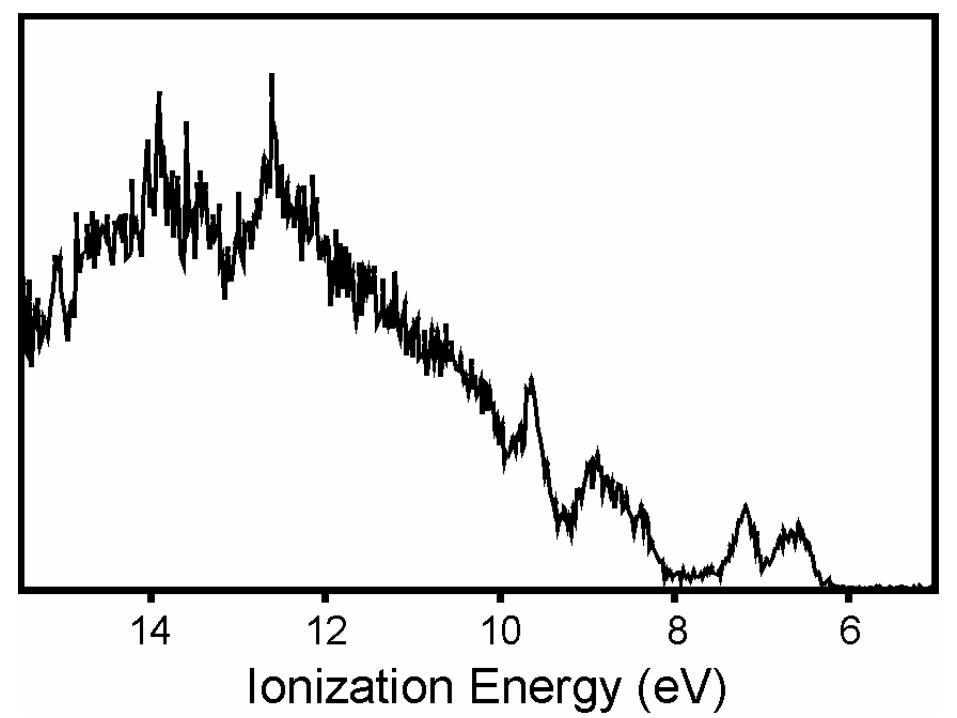

Figure S1. Full range PES spectrum of $\mathbf{2}$ 


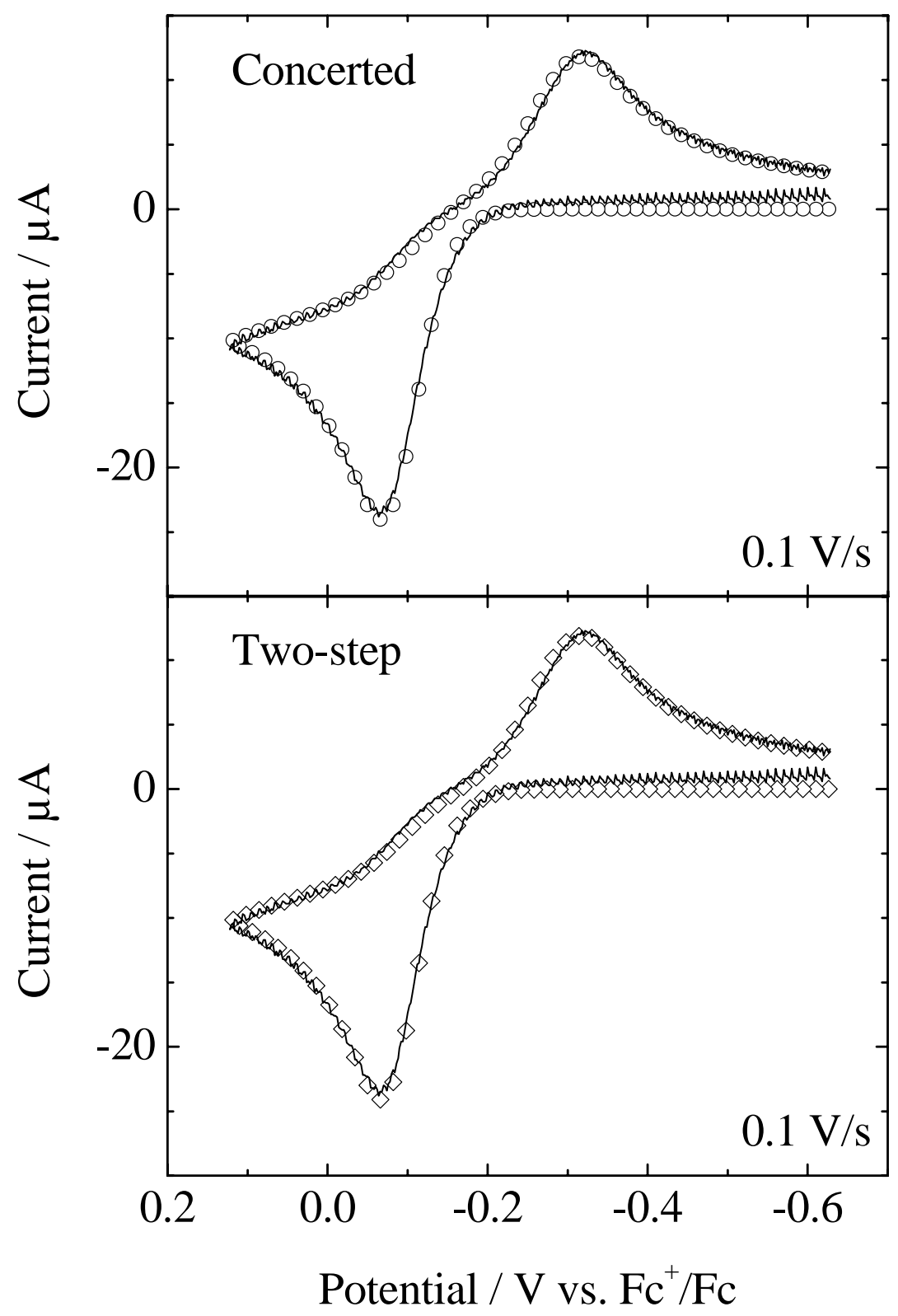

Figure S2 


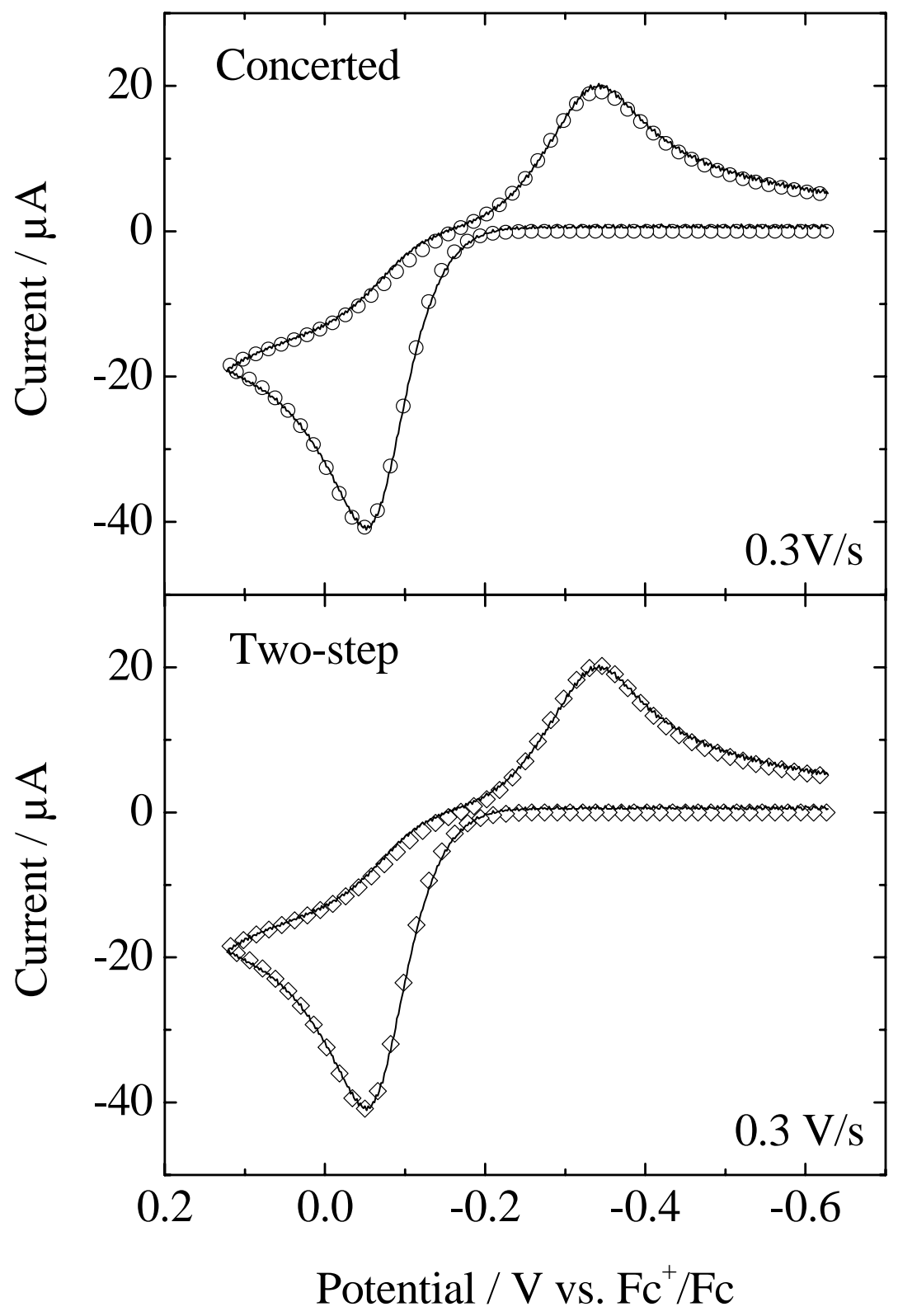

Figure S3 


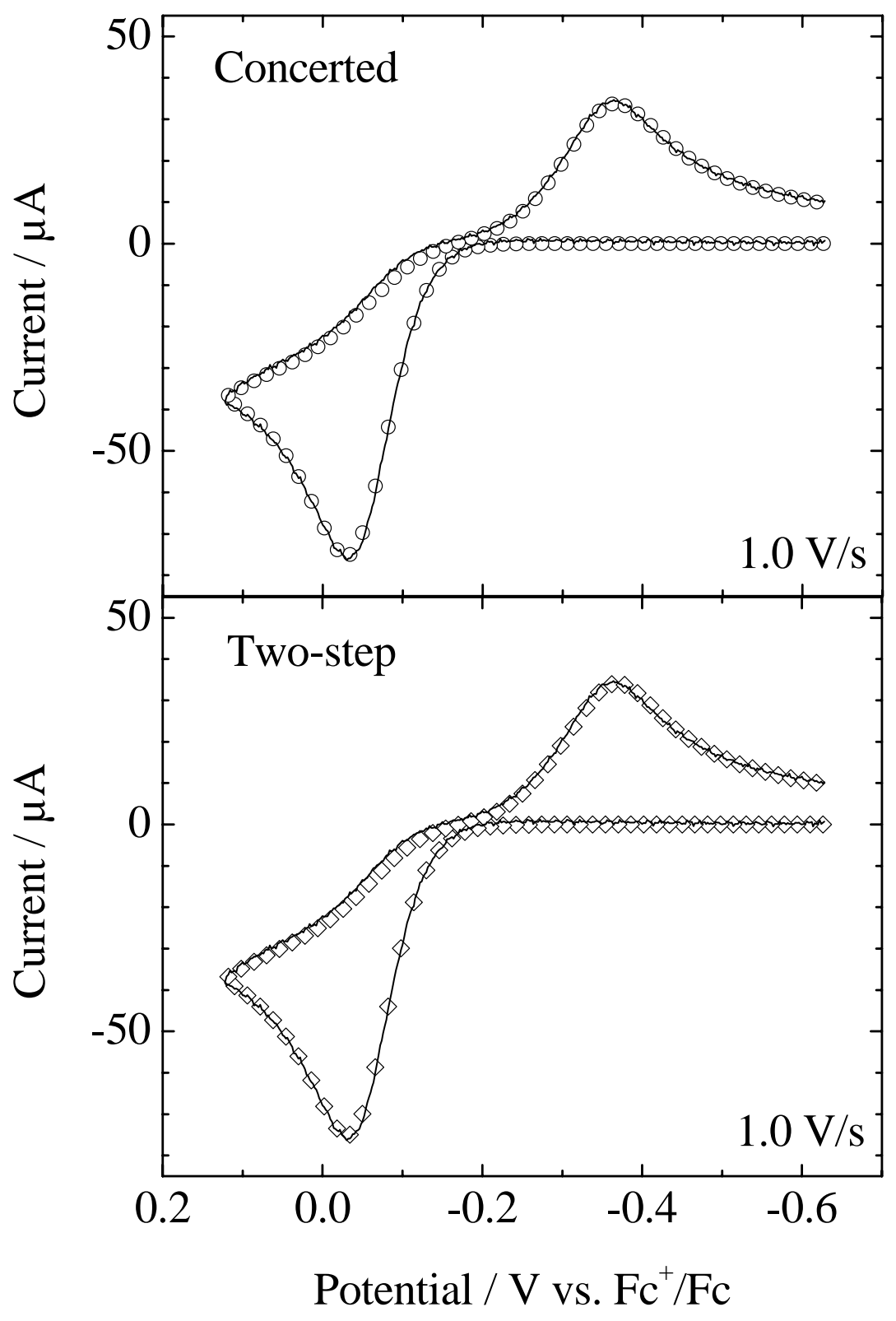

Figure S4 


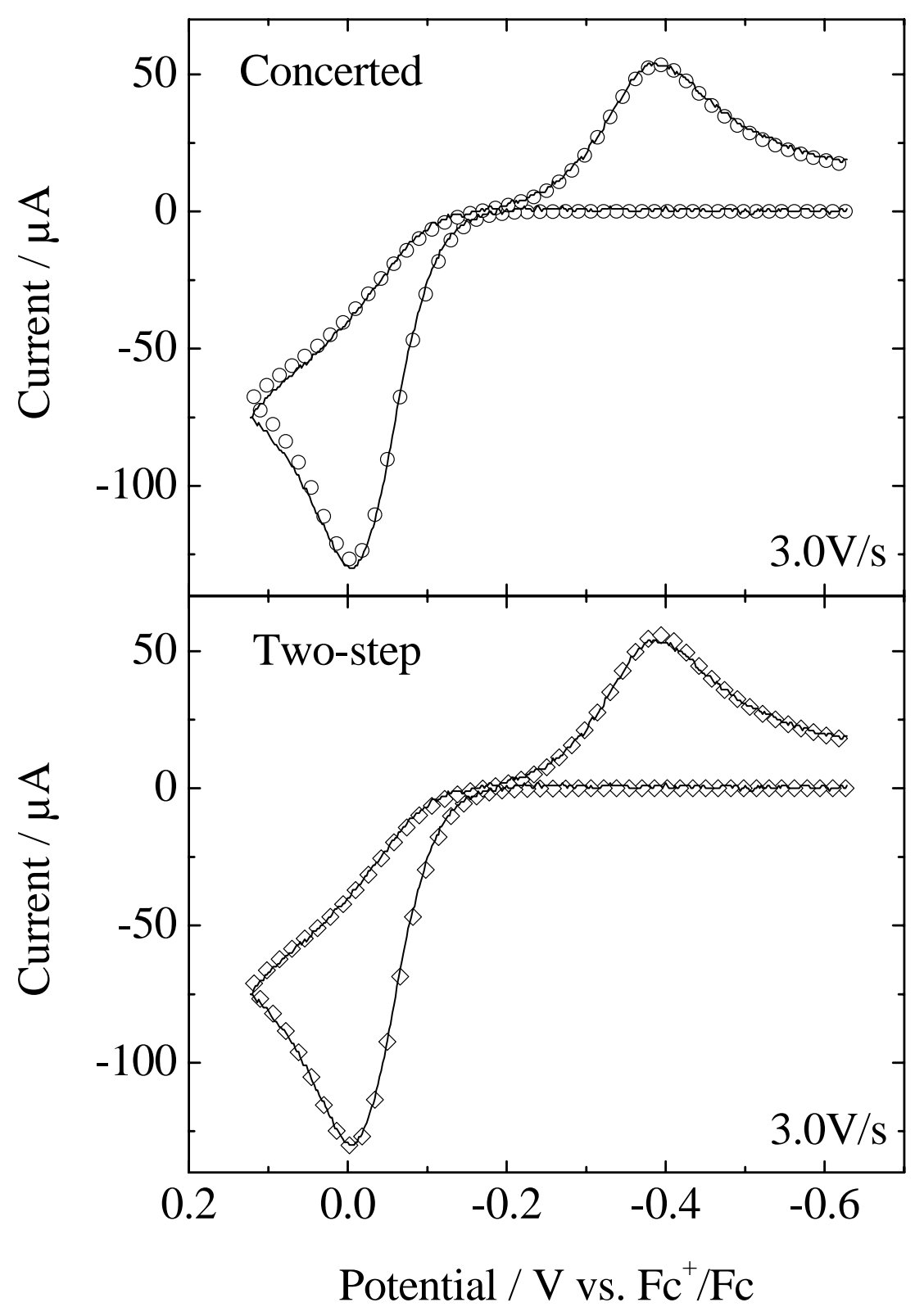

Figure S5 


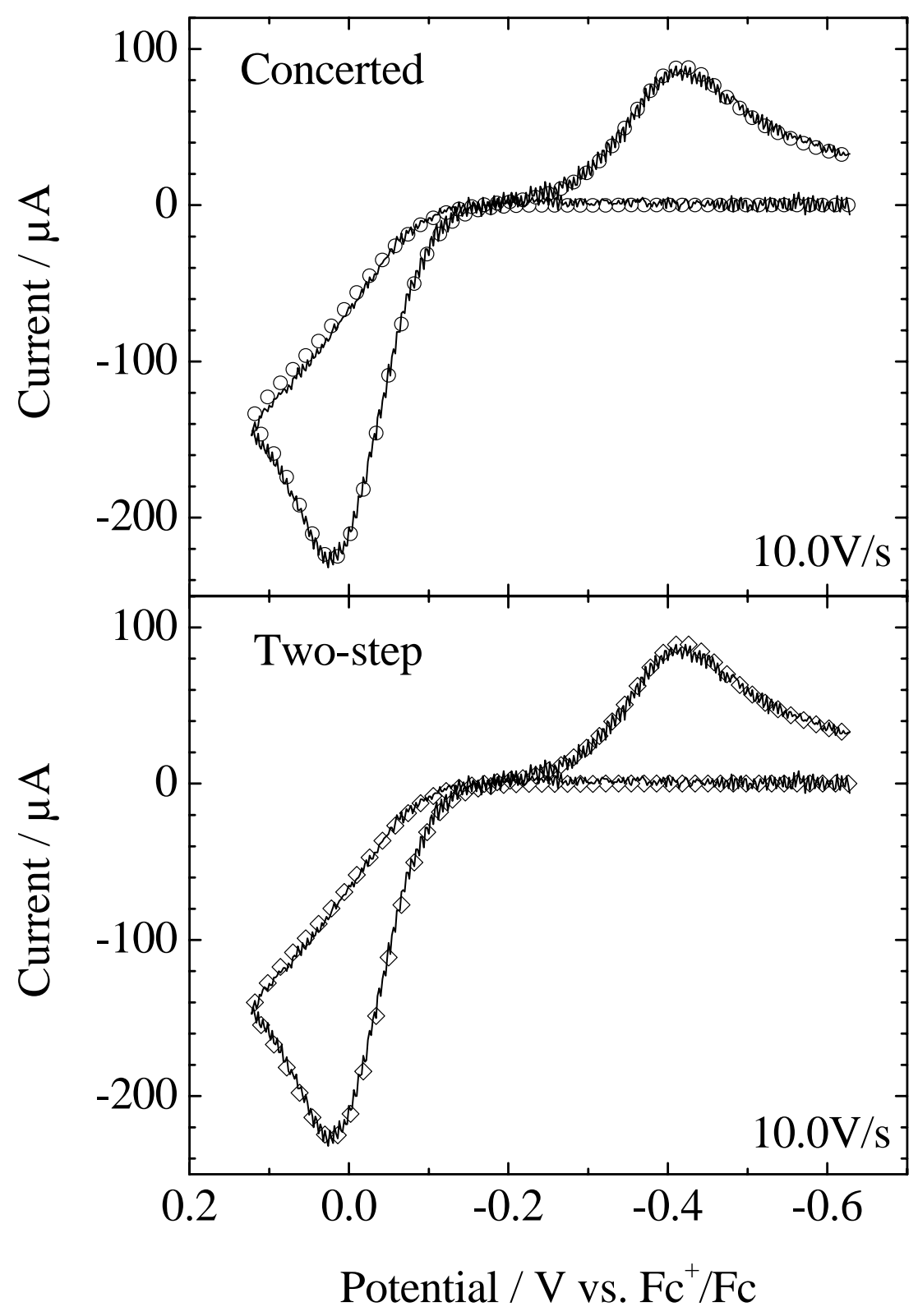

Figure S6 


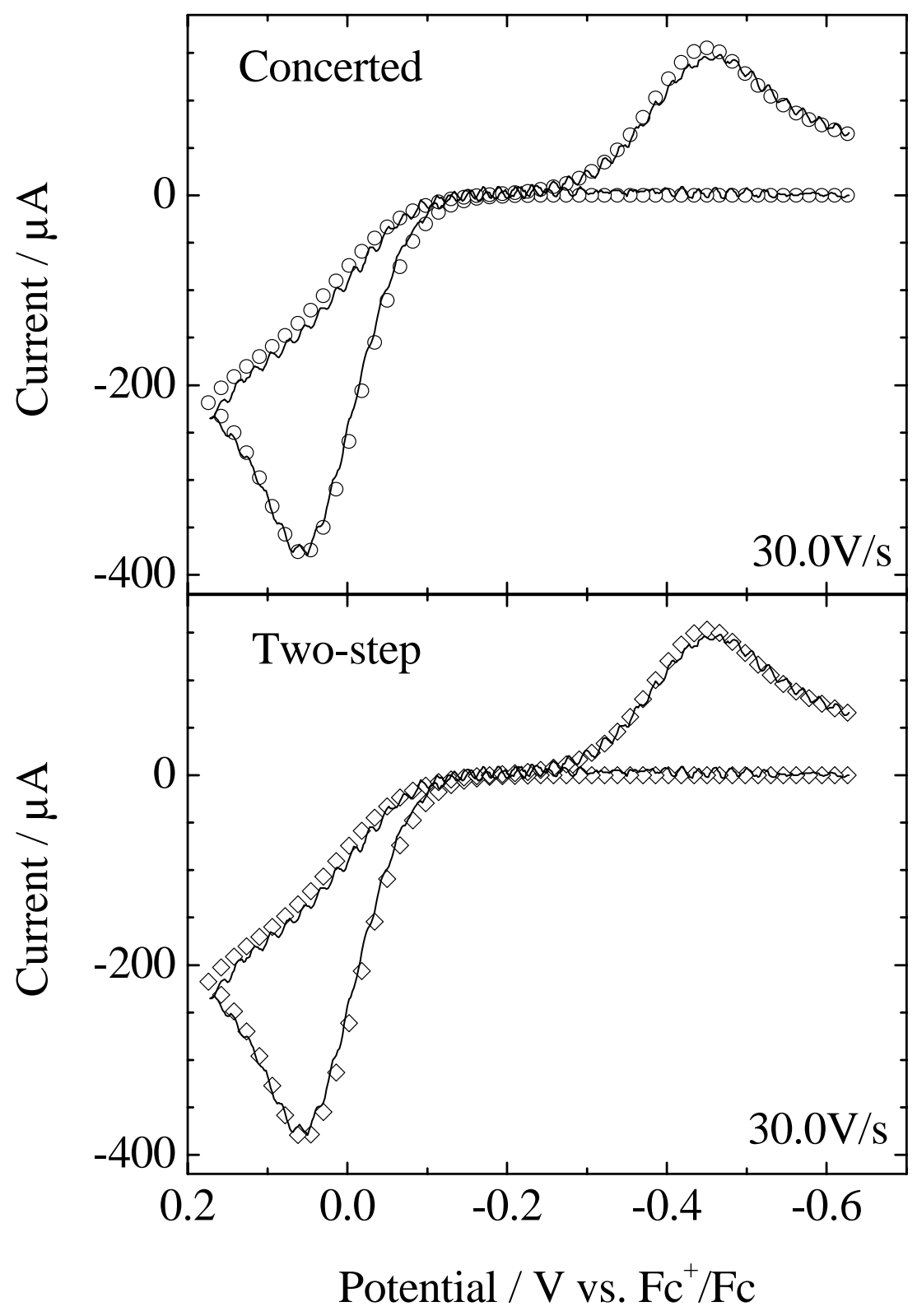

Figure S7 